\title{
Patterns and Sequelae of burn injury at the Jordanian Royal Medical Services rehabilitation center in 2005-2017: a cross-sectional study
}

\author{
Khalid Ali El-Maaytah ${ }^{1}$, Mohammed Nayef Albdour ${ }^{1}$, Mohammed Akef Aldabbas², Odai Musa El Sayegh', \\ Haneen Qasim Alshdowh ${ }^{4}$, Mohammed Saleh Khataybeh ${ }^{5}$
}

\begin{abstract}
${ }^{1}$ MD, Senior Plastic \& Reconstructive Surgery Specialist, Plastic Surgery Department, Royal Rehabilitation CenterRoyal Medical Services, Jordanian Armed Forces, Amman, Jordan

${ }^{2}$ MD, Plastic \& Reconstructive Surgery Specialist, Plastic Surgery Department, Royal Rehabilitation Center-Royal Medical Services, Jordanian Armed Forces, Amman, Jordan

${ }^{3}$ MD, Plastic \& Reconstructive Surgery Fellow, Plastic Surgery Department, Royal Rehabilitation Center-Royal Medical Services, Jordanian Armed Forces, Amman, Jordan

${ }^{4}$ RN, Lecturer of Nursing Faculty at The Royal Medical Services College of Allied Health Professions, Al Balqaa Applied University, Amman, Jordan

${ }^{5}$ RN, Plastic \& Reconstructive Surgery Registered Nurse, Royal Rehabilitation Center-Royal Medical Services, Jordanian Armed Forces, Amman, Jordan
\end{abstract}

\section{Type of article: Short Report}

\begin{abstract}
Background: Burns are not yet appropriately reported in Jordan; determining patterns provides critical input in construction of awareness programs and vital issues to be addressed while developing such programs to raise public awareness as well as to increase the safety measures in domestic settings, as prevention is better than cure. Objective: The aim of the study was to determine burns in Jordan in regard to patterns and sequelae.

Methods: In this cross-sectional study, 1,288 records of patients with burns at the burns unit of the Royal Jordanian Rehabilitation Center (RJRC) between 2005 and 2017 were studied. Age, gender, total body surface area (TBSA), location of burn, admission date and time, location of incidence and mortality. All data were analyzed using descriptive statistics and Chi-square test.

Results: Mean age was $31 \pm 26$ years; the male-to-female ratio was $1.56: 1$ and $41.8 \%$ of victims admitted were at or below 14 years of age. The proportions of males and females with burn injury was not statistically significant by age group $(\mathrm{p}=0.8)$. A total of $90.5 \%$ were in a domestic environment and $64.5 \%$ were the result of direct flame burn, followed by scalding burns in about $25.3 \%$. The most affected sites were limbs with the majority of patients with below $40 \%$ total body surface area (TBSA) affected and deep partial thickness. A further 218 cases were inhalational injuries. Mean of in-hospital stay was 18 days. The overall mortality rate was $14.6 \%$ and attributed to elevated TBSA, depth of the wound, presence of inhalational injury and flame type of burn. Age specific mortality were $7.9 \%$ and $19.15 \%$ in patient younger than 14 years of age and in older ones respectively

Conclusion: As most burns appeared to be in domestic settings, raising public awareness and increasing safety measures in domestic settings will hopefully decrease burn incidence and its consequences. Teaching first aid to the population can also be beneficial in reducing the morbidity and mortality of burn.

Keywords: Domestic burn, Direct flame burn, Pattern, Epidemiology, Jordan
\end{abstract}

Acronyms / Abbreviations:

RJRC: Royal Jordanian Rehabilitation Center; TBSA: Total Body Surface Areal RMS: Royal Medical Services; DFB: Direct Flame Burn.

\section{Corresponding author:}

Dr. Khalid Ali El-Maaytah, Plastic Surgery Department, Royal Rehabilitation Center-Royal Medical Services, Jordanian Armed Forces, Amman, Jordan. Tel: +962.790972645, Email: k_maaytah@yahoo.com

Received: July 28, 2018, Accepted: September 17, 2018, Published: June 2019

iThenticate screening: December 05, 2018, English editing: February 24, 2019, Quality control: March 12, 2019

This article has been reviewed / commented by three experts

Ethics approval: Ethics Committee of Jordanian Royal Medical Services (Ref: 7/2018).

(C) 2019 The Authors. This is an open access article under the terms of the Creative Commons Attribution-NonCommercialNoDerivs License, which permits use and distribution in any medium, provided the original work is properly cited, the use is non-commercial and no modifications or adaptations are made. 


\section{Introduction}

Burn, a distinct form of trauma with a devastating outcome, is amongst the most severe injuries an individual can endure. Burns are a major health problem worldwide, with elevated mortality and morbidity rates, and involving economic loss with even small burns. A variation of communities are affected the form of incidence and the cause of burns affected by factors such as local customs, sex, age, economic status, and social-environmental conditions (1). Managing burn injuries can take place at home or in a hospital setting depending on the severity and the anatomical location of the injury. Burns occur in different settings: domestic, industrial, occupational and others. In most cases, injury is preventable $(1,2)$. Domestic accidents related to burns are found to be the leading cause in developing countries (3-5).

Little attention is directed toward finding an epidemiological data base in Jordan, burn incidents are poorly reported. Only one previous study established epidemiological and demographical data regarding burn injuries in Jordan and that was confined to north of Jordan (6), data reflecting the regional status were found to be older than the expected 5-year period. Studies from turkey (7), Singapore (8), Iran (9-13), India (14), Egypt (15, 16), Saudi Arabia (17-19), Pakistan (20), Israel (21), and Kuwait (22, 23) were used in comparison. As there is significant lack of epidemiological studies about burns in Jordan, the general objective of this research was to determine the trends of injury, as it is crucial to assist in preventing injury and decreasing mortality and morbidity. This study focuses on establishing the corner stone of burn related epidemiological studies and providing updated information to enhance and develop awareness programs. In order to accomplish the preliminary goal of recognizing patterns of injury, this retrospective study was performed looking through files of patients who entered the burns unit to receive care in the Royal Jordanian Rehabilitation Center (RJRC) at the Royal Medical Services (RMS) Amman, Jordan, a tertiary care center specialized in orthopedic, reconstructive and aesthetic surgery containing a highly specialized critical care unit for burns patients. The burns unit is a central referral destination for burns victims in the kingdom for both private and public sectors as well as catering to burns victims from neighboring countries. Studying clients of this specific unit will help determine the leading cause of burn injury and highlight the primary incidence scenery to help advocate a better policy in preventing burns in the area.

\section{Material and Methods}

This cross sectional study was carried out in The Royal Jordanian Rehabilitation Center (RJRC) in February 2018. Data from January 2005 to December 2017 was used for analysis. The Royal Jordanian Rehabilitation Center (RJRC) is considered the first tertiary hospital and referral destination, with the primary unit for burns at the district since 1984. RJRC is a referral destination for multiple departments and health care sectors from inside and outside of Jordan. Institutional review board consent was submitted and obtained prior to data collection (Human Research Ethics Committee, Royal Medical Services, Amman, Jordan, Ref: 7/2018). Using the opportunity sampling technique of all data for patients admitted to the burns unit throughout the period of January 2005 to December 2017, a total of 1,288 admissions to the burns unit were included in the study. Data included the demographics, cause and type of burns and the affected total body surface area (TBSA) which are considered major risk factors for burn morbidity and mortality (22-25). Data preview was limited to the research team and for research purposes only. Data were analyzed and described using Microsoft Excel 2010. Descriptive statistics (central tendency measures, frequency, dispersion, and ratios) and Chi-Square test (goodness-of-fit).

\section{Results}

Investigating data flow during the time period January 2005 to December 2017, showed fluctuation in the total number of admissions, which ranged from 52 patients in 2008 to 135 in 2017 . Another elevation was noted in the year 2012 in which 134 patients were admitted, these years saw special admissions from neighboring countries going into armed conflicts (Iraq, Syria and Yemen). The ratio of male to female involvement remained consistent (1.56:1) throughout the 12-year period, a mean of 66.25 males, 44.88 females were admitted annually to the unit, and direct flame burns dominated as the main cause of admissions annually. Winter season also had the highest incident of admission each year of the study, mean age of admissions was $31 \pm 26$ years and ranged from 0-98 years. Through the years, the dominant age group was of those older than 14 years. During this 12 years period (20052017), 1,288 patients were admitted to the burns unit alone. The number of male patients was 790 (61\%) and 506 were females (39\%), male-to-female ratio was 1.56:1. The age range considered was from 1 day to 98 years, with a mean age of 31 years. Criteria for admission to the unit requires high risk burn patients, meanwhile the mild and moderate cases are admitted to regular wards of the RJRC and those records were not considered for this study and are recommended for investigation in future studies. A total of 1,080 patients admitted had TBSA burns of less than $40 \%$ ( $84 \%$ of total admitted cases). About $41.8 \%$ of the affected patients were aged at or below 14 years. Of these, mortality was $7.9 \%$ compared to $19.15 \%$ in those older than 14 years of age. 
The majority of cases admitted were males (61\%) and most of them older than 14 years of age (59\%).This observation raised a question as to whether gender is implicated as an influential factor to being at risk of acquiring burns in a certain age group. A goodness of fit (Chi-Square) analysis to determine the gender differences in distribution of burn injuries across the age group of $\leq 14$ years old and those older than 14 years of age, showed that the male gender was associated with a higher incident rate in the older age groups. Male incident of 464 and female 293 in the age group of $>14$ years and 322 male, 209 female in the $\leq 14$ year o0ld group suggested that males have a higher rate of involvement in the older age group. According to Chi-Square test (goodness of fit) the proportion of gender with burn injury was equally distributed by the age groups and there were no difference in gender distribution across age groups $(\mathrm{p}=0.812827)$. In addition, there was no statistical evidence to establish gender differences in the distribution of burn injury according to age at which the burn occurred; males and females were equally distributed across the age groups. Seasonal variations in numbers of admissions were noted, and demonstrated higher numbers in winter season where about $58 \%$ of patients were admitted (September to January), with direct flame burns responsible for $64.5 \%$ of the total incidences and $89 \%$ of mortality rate. Diurnal variations of admissions placed admissions after midnight as scarce $(<1 \%)$, while the difference between early morning and the afternoon period was absent. Regarding accidental burns, $90.5 \%$ of them took place in a home environment $(55 \%$ of those were males), $4.5 \%$ were affected at work, $1 \%$ war victims and the remaining varied between suicide attempts, motor vehicle accidents, drug reactions and criminal intent (Table 1).

Table 1. Relationship between Epidemiology of burn and mortality rate

\begin{tabular}{|l|l|l|l|l|}
\hline Variables & Total No. in group & Mortality & $\%$ \\
\hline \multirow{2}{*}{ Age (year) } & $\leq 14$ & 539 & 43 & 7.98 \\
\cline { 2 - 5 } & $>14$ & 757 & 145 & 19.15 \\
\hline Male & 790 & 104 & 13.16 \\
\hline Female & 506 & 84 & 16.6 \\
\hline Less than 40\% TBSA & 1080 & 54 & 5 \\
\hline TBSA 40\% and above & 216 & 134 & 62.04 \\
\hline
\end{tabular}

Direct flame burn (DFB) was the leading cause in $64.5 \%$ of cases followed by scald burn $(25.3 \%)$, the ratio was 2.5:1. Electrical burns accounted for 3.1\%, and chemical burns 3.2\%. The rest of these were combined injuries, patients with toxic epidermal necrolysis (TEN syndrome), and carbon monoxide poisoning. The extremities were the most affected body site with a total of 879 patients $(68.3 \%)$, of these $21 \%$ were circumferential. A total of 124 cases had head and neck involvement (9.6\%); the ratio was 7.08:1. About 13\% reported having trunk burn, while the others were classified as multiple affected sites. Partial thickness superficial burns were observed in only 92 patients (7.1\%), most admissions presented with deep partial thickness burns, with a total of 914 cases $(70.9 \%)$ and 21 patients $(1.6 \%)$ of total admissions had full thickness burns. Two hundred eighteen patients were diagnosed with inhalational injury (16.9\%). Intubation took place in 395 cases, and 184 patient needed escharotomy. Graft and flap procedures were performed on 980 patients, $76 \%$ of total admissions. The average of stay at the unit was 18 days. The annual distribution of burns admission is shown in Figure 1.

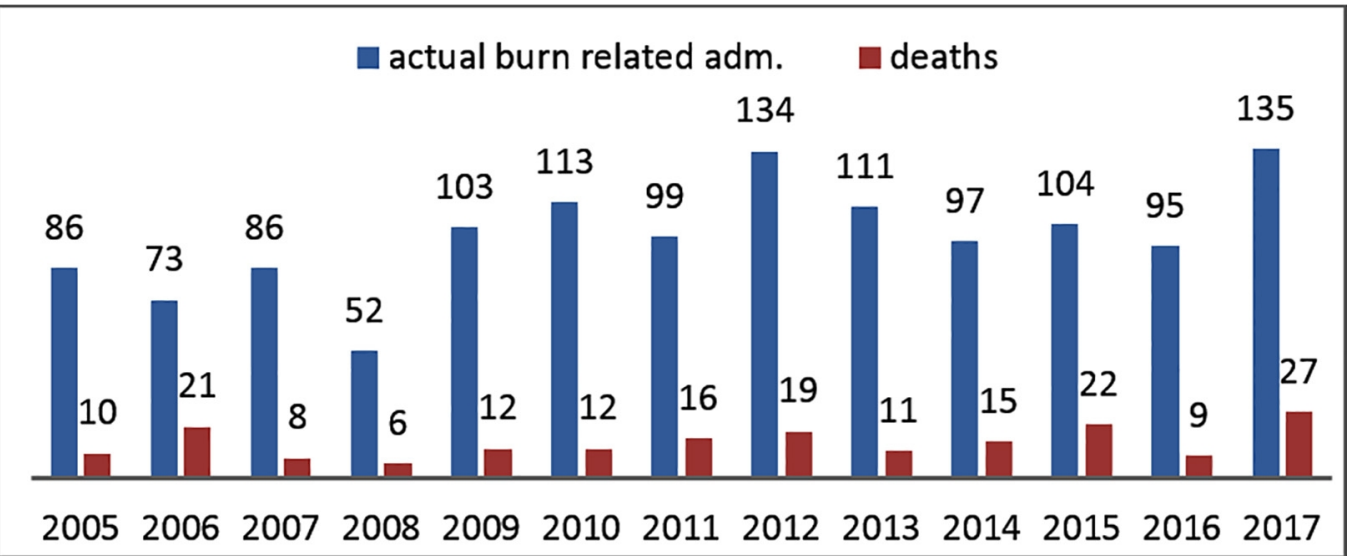

Figure 1. The annual distribution of burns in the study population

The overall mortality was 188 patients $(14.6 \%) ; 104$ patients were males and 84 were females. Of the 539 cases at or below the age of 14 years, there were 43 mortalities, while there were 145 mortalities above 14 years of age. A total 
of $89 \%$ of mortalities were due to direct flame burn, of which, $81 \%$ had major and full thickness burn and $42 \%$ had an association with inhalational injury or were mechanically ventilated.

\section{Discussion}

Epidemiological studies regarding patterns of burn injury in Jordan occur on a very low scale, and are undercirculated and marginalized (6). Looking at the demographics of this study, male to female proportion is similar to those of previous publications (6), surrounding countries and also the world (7, 20,26). Adolescents and adults formed the greatest portion of cases admitted, which is also close to results published by studies performed in other Middle Eastern countries $(8,15,16,18,20,22,27,28)$ where the vulnerability of adolescents was first supported and then later reports of higher influence on the adult population,. This supports that emphasis should be placed on males, adolescents and adults when designing the awareness programs, which contradicted the assumption of the researcher that adult females are more prone to burn type of injury. Previous literature implicated males for higher involvement in acquiring burn injury $(23,29)$, adult males sustained a higher rate of injury in this case also. The observed numbers suggested higher male involvement though this hypothesis were rolled out when statistical analysis failed to demonstrate a difference among gender groups that are stratified by age. This result could be attributed to the current social changes seen in Jordan; in the past women were confined to home but are now on an equal footing with men. Women are responsible for working and providing, and are even involved in the military corps, while men also do house chores. Gender difference is apparently diminished in society and burn incident also reflects that. The observed larger male involvement in the older age group is suggested for further investigation.

The seasonal and diurnal variations were considered as a major influential element in developing burn injuries, winter season had increased burn incidence; gas and other fossil fuels are often used in winter for heating options and this is thought to be the cause of the increased incident count during this season. This was contrary to Carroll et al. (30) who reported summer as higher incidence, while other research $(3,31)$ found spring to be common. Ayoub at el. (32) and Metin et al. (33) emphasized the winter for the prevalence of burn injuries, which is in harmony with our results. The results reflect that the optimal time to maximize preventive-and-awareness measures publicity is during the winter season.

Determining that environmental element as the location of the incident varies, helps direct preventive programs as well as emphasize safety measures to be adopted in various environments. The home environment is considered the commonest location of incidence $(7,17-20)$, it is suggested that the kitchen contains the highest risk of fire since gadgets are operated on fossil fuel; ethanol gas remains to be adopted by the government and society as the main choice for heating and cooking. Identifying the type of burns experienced more frequently will also guide efforts in developing a specialized efficient preventive program. DFB was the cause with highest prevalence in our study, this is in consistency with published data $(7,13,17,18)$ and liquid (scald) burns were reported as the second highest. There were some suicide attempts reported, which goes with previous studies $(9,11,13,19)$. Electrical burns were reported in only $3.1 \%$; in this study, electrical burns were due to high voltage electrical current, which was the same situation in developed countries $(16,34)$.

Mortality is a major outcome in any type of injury. Burns have no difference to that, with its reputation of being lethal. Acknowledging the mortality rates was necessary for the research. Overall mortality in this study fell close to other published works $(20,21,35)$, and less than others which might reach as much as $37.6 \%$ (32). Mortality was mostly of domestic occurrence. Children at or below 14 years have a lower risk of dying, this was in contrast to the results of Anlatici et al. (36). At home, flame burns accounted for most of the deceased patients; not only does it affect large body surface areas, but also it increases susceptibility of developing inhalational injury in a closed space area, the finding of which is found to be similar to that in other published data $(18,25,36)$ that urge a focus to be placed towards home safety measures.

Mean hospitalization period was 18 days, compared to Saffle et al. (37) from the United States who reported 13.5 days, Mahaluxmivala et al. (18) from Saudi Arabia who reported 16.4 days and Bang RL (22) from Kuwait with 38 days in 1996 and 16 days in the year 2000 (23). Minimizing hospital length of stay, providing efficient care and minimizing expenditure of health care expenses is a global indicator of the health industry. Being only the second study of its kind in Jordan implies a huge shortage in epidemiological data. This directed effort will hopefully influence this situation positively on other health providing sectors and we will begin to expand this effort to cover the issue in updates. Limitations included shortage of participating hospitals, lack of burn care specialized units and 
centers, limited cooperation between healthcare sectors as well as the lack of long term burn sequelae correlation with the initial injuries in the outpatient records.

\section{Conclusions}

Direct flame burns in the domestic environment influencing adolescents and adults are shown to be the main cause of burn injuries and also the leading cause of mortality. This highlights the pattern of burn injury in Jordan. Preventive measures and educational programs should emphasize on home environment control and alterations toward safer behaviors as well as spreading awareness in homes, teaching first aid measures in schools to parents and students, and through media, which we believe, may lessen the incidence and the severity of burns. Conducting further research and continuous updates are recommended on the issue.

\section{Acknowledgments:}

We would like to convey thanks to the Royal Medical Services for the unfailing support of research programs, special gratitude to the royal Jordanian Rehabilitation Center presented by Dr. Mohammad Abu Al Samin and the entire staff for their cooperation and a special thanks to Lieutenant Montaser El- Maaytah for facilitating the data collection.

\section{Conflict of Interest:}

There is no conflict of interest to be declared.

\section{Authors' contributions:}

KAA and HQA conceptualized and designed the research project. KEA, OME, HQA, and MSK performed the data collection. All authors contributed to the analysis or interpretation of data, drafting and revising the manuscript. All authors provided significant input in the manuscript, and read and approved the final version of it. All authors are accountable for all aspects of the work in ensuring that questions related to the accuracy or integrity of any part of the work are appropriately investigated and resolved.

\section{References:}

1) World Health organization (WHO). Burns. Retrieved 2018. Available from: http://www.who.int/newsroom/fact-sheets/detail/burns.

2) Amirican Burn Association. Amirican burn association. 2016. Available from: http://ameriburn.org/who-weare/media/burn-incidence-fact-sheet/

3) Chien W, Pai L, Lin C, Chen H. Epidemiology of hospitalized burns patients in Taiwan. Burns. 2003; 29: 582-8. PMID: 12927984

4) Jie X, Baoren C. Mortality rates among 5321patients with burns admitted to a burn unit in China: 1980-1998. Burns. 2003; 29: 239-45. PMID: 12706617.

5) Han T, Kim J, Yang M, Han K, Han S, Jung J, et al. A retrospective analysis of 19, 157 burns patients: 18year experience from Hallym Burn Center in Seoul, Korea. Burns. 2005; 31: 465-70.

6) Ziad AB, Thekraiat MQ, Hamzeh AB, Muhmammad RK. Pattern of burn injury at north of Jordan. Int J Burn Trauma. 2018; 8(1): 1-5. PMID: 29531853, PMCID: PMC5840313.

7) Tarim A, Nursal T, Yildirim S, Noyan T, Moray G, Haberal M. Epidemiology of pediatric burn injuries in southern Turkey. J Burn Care Rehabil. 2005; 26: 327-30. PMID: 16006839.

8) Song C, Chua A. Epidemiology of burns injuriesin Singapore from 1997-2003. Burns. 2005; 31(S1): S18-26. doi: 10.1016/j.burns.2004.10.005. PMID: 15649612.

9) Saadat M, Bahaoddini A, Mohabatkar H, Noemani k. High incidence of suicide by burning in Masjid-iSulaiman (southwest of Iran), a pollutedarea with natural sour gas leakage. Burns. 2004; 30: 829-32. doi: 10.1016/j.burns.2004.06.003. PMID: 15555796.

10) Saadat M. Epidemiology and mortality of hoshospitalized burn patients in Kohkiluye va Boyerahmad province (Iran): 2002-2004. Burns. 2004; 31: 306-9. doi: 10.1016/j.burns.2004.10.012. PMID: 15774285.

11) Maghsoudi H, Garadagi A, Jafary G, Azarmir G, Aali N, Karimian B, et al. Women victims of self-inflicted burns in Tabriz, Iran. Burns. 2004; 30: 217-20. doi: 10.1016/j.burns.2003.10.010. PMID: 15082346.

12) Groohi B, Alaghehbandan R, Lari A. Analysis of 1089 burn patients in province of Kurdistan, iran. Burns. 2002; 28: 569-74. PMID: 12220915.

13) Groohi B, Rossignol A, Barrero S, Alaghehbandan R. Suicidal behavior by burns among adolescents in Kurdistan, Iran: a social tragedy. Crises. 2006; 27: 16-21. doi: 10.1027/0227-5910.27.1.16. PMID: 16642911. 
14) Prasenjit G, Pankaj S, Amit Kumar S, Tukulu T. Five-year epidemiological study of burn patients admitted in burns care unit, Tata Main Hospital, Jamshedpur, Jharkhand, India. Indian Journal of Burns. 2016; 24 : 41-6. doi: 10.4103/0971-653X.195536.

15) Mostafa M, Burhan A, Abdullah A. A retrospective study of 5505 burned patients admitted to Alexandria Burn unit. Annals of the MBC. 1990; 3(4).

16) Hemeda M, Maher A, Maboruk A. Epidemiologyof burns admitted to Ain Shams university burn unit cairo, eygept. Burns. 2003; 29(4): 353-8. PMID: 12781613.

17) Hegazi M, Ibrahim E. The Pattern and outcome of burn injuries at burn unit in Saudia Arabia: retrospective analysis of 501 consecutive patients at a burn unit in Saudi. Ann Saudi Med. 1991; 11(3): 255-9. PMID: 17588098.

18) Mahaluxmivala S, Borkar A, Mathur A, Fadaak H. A retrospective study of etiopathological and preventive factors in a burns unit in Saudi arabia. Burns. 1997; 23: 333-7.

19) Alsalman A, Algadiem E, Alalwan M, Farag T. Epidemiology of infant burn in Eastern Saudi Arabia. Saudi Med J. 2015; 36(3): 324-7. doi: 10.15537/smj.2015.3.10683. PMID: 25737175, PMCID: PMC4381017.

20) Iqbal T, Saaiq M, Ali Z. Epidemiology and outoutcomeof burns: early experience at the country's first national burns centre. Burns. 2013; 39: 358-62. doi: 10.1016/j.burns.2012.07.011. PMID: 22867734.

21) Harats M, Peleg K, Givon A, Kornhaber R, Goder Jaeger M, Haik J. Burns in Israel: demographic, etiologic and clinical trends, 1997-2003. Isr Med Assoc J. 2007; 9: 659-62.

22) Bang R, Ghoneim I. Epidemiology and mortality of 162 major burns in Kuwait. Burns. 1996; 22 : $433-8$. PMID: 8884000.

23) Bang R, Sharma P, Gang R, Ghoneim I, Ebrahim M. Burn mortality during 1982 to 1997 in Kuwait. Eur J Epidemiol. 2000; 16(8): 731-9.

24) Fazeli S, Karami-Matin R, Kakaei N, Pourghorban S, Safari-Faramani R, Safari-Faramani B. predictive Factors of Mortality in Burn Patients. Trauma Mon. 2014; 19(1): e14480. doi: 10.5812/traumamon.14480. PMID: 24719826, PMCID: PMC3955925.

25) Muller M, Pegg S, Rule M. Determinants of death following burn injury. Br J Surg. 2001; 88(4): 583-7. doi: 10.1046/j.1365-2168.2001.01726.x. PMID: 11298629.

26) Kobayashi K, Ikeda H, Higuchi R, Nozaki M, Yamamoto Y, Urabe M, et al. Epidemiological and outcome characteristics of major burns in Tokyo. Burns. 2005; 31: 3-11. doi: 10.1016/j.burns.2004.10.007. PMID: 15649614.

27) Komolafe O, James J, Makoka M, Kalongeolera L. Epidemiology and mortality of burns at the Queen Elizabeth central hospital Blantyre, Malawi. Cent Afr J Med. 2003; 49: 130-4. PMID: 15301466.

28) Oluwatosin O. Burns in Africa. Afr J Trauma. 2004; 2: 20-5.

29) Blom L, Klingberg A, Laflamme L, Wallis L, Hasselberg M. Gender differences in burns: A study from emergency centres in the Western Cape, South Africa. Burns. 2016; 42(7): 1600-1608. doi: 10.1016/j.burns.2016.05.003. PMID: 27262931.

30) Carroll S, Gough M, Eadie P, McHugh M, Edwards G, Lawlor D. A 3-year epidemiological review of burn unit admissions in Dublin, Ireland 1988-1991. Burns. 1995; 21: 379-82.

31) Dedovic Z, Brychta P, Koupilova I, Suchanek I. Epidemiology of childhood burns at the burn center in Brno, Czech Republic. Burns. 1996; 22: 125-9.

32) Ayoub A, Kosatsky T, Smargiassi A, Bilodeau-Bertrand M, Auger N. Risk of hospitalization for fire-related burns during extreme cold weather. Environ Res. 2017; 158: 393-8. doi: 10.1016/j.envres.2017.07.001. PMID: 28689030.

33) Metin N, Alethea T, Tobias V, Nicholas S, David B, Peter D. Cold burn injuries in the UK: the 11-year experience of a tertiary burns centre. Burns Trauma. 2016; 4:36. doi: 10.1186/s41038-016-0060-x. PMID: 27843971, PMCID: PMC5105282.

34) Abrol A, Saraf R, Singh S. Thermal and electrical burns in Jammu province. J K Science. $2005 ; 7: 61$-63.

35) Mason SA, Nathens AB, Byrne JP, Gonzalez A, Fowler R, Karanicolas PJ, et al. Trends in the epidemiology of major burn injury among hospitalized patients: A population-based analysis . J Trauma Acute Care Surg. 2017; 83(5):867-74. doi: 10.1097/TA.000000000001586.

36) Anlatici R, Ozerdem O, Dalay C, Kesiktaş E, Acartürk S, Seydaoğlu G. A retrospective analysis of 1083 Turkish patients with serious burns. Part 2: burn care, survival and mortality. Burns. 2002; 28: 239-43. PMID: 11996854.

37) Saffle J, Davis B, Williams P. Recent outcomes in the treatment of burn injury in the United States: a report from the American Burn Association Patient Registry. J Burn Care Rehabil. 1995; 16: 219-32. 